\title{
Transtibial Near Anatomic Versus Accessory Anteromedial Portal for Anatomic Single Bundle A.C.L Reconstruction
}

\author{
H.M.Bassiony, M.G.Montaser, A.S.Ebrahim and A.E.Zayed \\ Orthopedic Surgery Dept., Faculty of Medicine, Benha Univ., Benha, Egypt \\ E-Mail: Zayed6@gmail.com
}

\begin{abstract}
The purpose of this study was to compare the clinical outcomes of BPTB ACL reconstruction using the AMP or the TT technique for the femoral tunnel drilling. A Medline search was not ableto recognize any examination legitimately contrasting the clinical results of the AMP and the TT methods. The writing search distinguished test examines distributed from 1966 to March 2009 where in any event one gathering went through arthroscopic autologous BPTB ACLreconstructions utilizing either the AMP or the TT procedure for the femoral passage drilling.Twenty-one examinations, including a sum of 859 patients (257in the AMP and 602 in the TT gathering), were remembered for this investigation. The AMP bunch exhibited altogether before re-visitation of run and fundamentally more prominent scope of movement, Lachman test esteems, and KT-1000 arthrometer estimations. The utilization of the AMP evoked more noteworthy knee dependability and scope of movement esteems, and prior re-visitation of run contrasted with the TT technique.These results may show a likely advantage of the AMP over the TT strategy. Notwithstanding, as the advantages of the AMP were not gotten in the mid and long haul subsequent meet-ups, generally there is no authoritative proof now to infer that one procedure is better than the other. Randomized controlled preliminaries legitimately contrasting the utilization of the two procedures and long haul subsequent meet-ups will help explain which one, ifany, gives best clinical results.
\end{abstract}

\section{Introduction}

Careful reproduction is presently generally acknowledged as the treatment of decision for utilitarian knee precariousness because of front cruciate tendon (ACL) inadequacy particularly in youthful patients who are associated with truly high requesting exercises [1]. This system is notable for its capacity to permit a person to re-visitation of preinjury action levels, which may not be accomplished with noncareful treatment [2]. Regardless of the impressive examination zeroed in on ACL reproduction, the expanded danger of early knee osteoarthritis and the presence of rotational insecurity post-medical procedure have not been completely researched at this point.

Accordingly, contention remains with respect to the best procedure for reproduction; in this manner, it is as yet the subject of broad examination [3]. Among the numerous components that decide the result following ACL remaking, the situation of the passages made for join obsession is known to be of basic impact, and malpositioning of the femoral passage happens multiple times more much of the time than malpositioning of the tibial passage [4].

Femoral passage position is more basic since it is nearer to the focal pivot of knee turn, and malpositioning of the femoral passage has been accounted for to be the most incessant reason for unite disappointment [5].

Foremost Cruciate Ligament (ACL) burst is one of the most continuous muscular game wounds, with a yearly occurrence of 35 out of 100,000. In contrast to a huge number and tendons, a mid-substance (ACL) tear can't recuperate and the appearance is moderate to extreme handicap with "giving way" scenes in exercises of day by day living, particularly during sport exercises. Further, it can make wounds other delicate tissues in the knee, especially the menisci, and lead to beginning stage knee osteoarthritis [6].

Thusly, arthroscopic (ACL) remaking is one of the regularly performed muscular medical procedures. The objective of reproduction is to duplicate the elements of the local front cruciate tendon [7].

Suboptimum results and ligament changes in the knee joint after a long haul (ACL) remaking follow up are prompting a change in careful procedure from the customary transtibial two entrance method to the anatomical single-pack three entryway strategy, which all the more intently reestablishes the local (ACL) life systems [8].

The point of this work was to reflectively look at the radiological and clinical results of arthroscopic ACL recreation utilizing the TT and AMP penetrating strategies for femoral passage placement.

\section{Patient and method}

This orderly survey was finished incorporating patients with ACL-inadequate knees who went through arthroscopic anatomic single group ACL reproduction. All recreations are finished utilizing quadrupled strands of semitendinosus and gracilis ligaments autografts. In all cases, the femoral side is fixed utilizing endobutton (Smith and Nephew). Patients have multiligamentous injury, chondral sore, extreme osteoarthritis and halfway ACL injury are prohibited structure this examination.

For incorporation, contemplates were needed to be: [1] planned exploratory and semi test examines: [2] utilizing the one-cut arthroscopi autologous BPTB ACL remaking; [3] have referenced the femoral passage boring method: [4] a base 1-year development; and [5] have comparative recovery conventions. Studies including modifications, allografts, and autografts other than BPTB were rejected. 
All examinations were summed up by the utilization of an information extraction structure amied to distinguish the femoral boring strategy, study configuration, test size, development, and obsession methods, beneficial data with respect to recovery, extra required strategies, and entanglements was removed from all investigations. Information on the general IKDC, Lysholm scores, movement level, scope of movement (ROM), quality appraisals, knee steadiness (Lachman and Pivot Shift sign tests, and KT-1000 arthrometer estimations), and knee radiographic changes were gathered and defined by short (1-2 years), mid - (35 years), and long haul (6-10 years), mid (3-5 years), and long - term (6-10 years) subsequent meet-ups, each examination was painstakingly dissected by two free analysts. Inconsistencies between analysts were investigated to show up at agreement information. For those examinations not directing the development at a solitary point as expected, the mean subsequent time was accounted for.

Unmistakable insights were utilized to sum up the segment qualities of the subjects partaking in all examinations, and an autonomous t-test was utilized to look at segment information between the two gatherings. The Chi-square measurable test was utilized to look at clear cut factors between gatherings. The factual examination was separated for the length of development in 3 gatherings: 1-2 years, 3-5 years, and 6-10 years.

\section{Results}

Any concentrate legitimately thought about the clinical results of the AMP and TT methods. Eight investigations utilizing the AMP method and 13 utilizing the TT strategy were found. Four of the 8 investigations utilizing the AMP were distributed by the gathering of Pinczewski and allude to similar example of patients. Hence, AMP considers included 257 patients in five distinct examinations. For each subsequent period, information from the investigations of the gathering of Pinczewskin was just taken once. Each of the 13 TT considers included 602 patients. An aggregate of 859 patients were associated with this investigation. Table (1) sums up the fundamental qualities of the included examinations.

The subsequent just alludes to those going through AC $\mathrm{L}$ reconstuction utilizing the AMP or the TT strategy. Mean age was 27.5 years for the AMP gathering and 25.8 years for the TT gathering. The male:female apportion was 1.7 for the AMP gathering and 1.8 for the TT gathering.

Every one of the 21 investigations had comparable restoration conventions table (2). Patients from the AMP bunch started running essentially sooner than those from the TT gathering (mean 7.5 weeks and 11.8 weeks, individually. Additionally the AMP bunch got back to full games sooner than the TT gathering, despite the fact that the current contrasts was not factually critical (mean 20 weeks and 30.3 weeks, individually). Most investigations supported full ROM and full weight bearing from the main day after medical procedure, and didn't utilize post-usable supports.

Table (3) shows the extra techniques and the Complications after the ACL recreation. Just 2 examinations (one in each gathering) didn't report an extra medical procedure after the ACL recreation. Halfway meniscectomies, cyclops extractions, and screw evacuation are among the most well-known extra medical procedures needed after the ACLreconstruction. Fourty-one of every one of the 859 patients (4.77\%) continued a contralateral ACL tear. The join disappointment rate was $5.7 \%$ in the AMP and $2.3 \%$ in the TT gathering. Intra-articular diseases, profound venous apoplexy, or nerve wounds were just found in 2 investigations (both in the TT gathering).

All examinations announcing the Overall IKDC score communicated the results as a level of patients with grades $\mathrm{AB}$ and $\mathrm{CD}$ Table (4). Just 3 investigations ( 1 in the AMP and 2 in the TT gathering) didn't evaluate the IKDC score and were excluded from the measurable examination. This examination included an aggregate of 409 patients in the 1-2-year subsequent period, 296 for the 3-5-year time frame, and 277 for the 6-10-year time frame. No measurably huge contrasts were found for any subsequent period in Overall IKDC between gatherings Table (5). Four investigations in the AMP and 2 in the TT bunch revealed the Lysholm scores as the level of patients with Excellent (95-100), Good (84-94), Fair $(65-83)$, or Poor $(<65)$ scores.

Knee soundness was surveyed in all examinations Table (6).

Thirteen investigations announced the Lachman test esteems as the level of patients with grades 0,1 , and study gave the mean Lachman test as a 0-1-2 scale 50], and 7 examinations didn't report information on Lachman test Table (6). The factual examination for the Lachman test included 213 patients for the 1-2-year development, 232 patients for the 3-5-year development, and 245 patients for the 6-10-year development. The AMP bunch showed more noteworthy front back knee steadiness estimated through the Lachman test contrasted with the TT bunch for the 1-2-year development, despite the fact that the thing that matters was not kept up for the remainder of subsequent periods Table (6). Rotational knee security was estimated through the turn move sign test in 14 examinations Table (6). The other 7 examinations didn't report information on the rotational knee strength.

The measurable investigation included an aggregate of 344 patients for the 1-2-year subsequent period, 248 patients for the 3-5-year development, and 215 patients for the 6-10-year development. No measurably critical contrasts were found for any subsequent period in the turn shiftsign test between gatherings Table (6). The foremost posteriorinstrumented knee laxity was estimated with the KT-1000 arthrometer in all investigations (Table 7). KT-1000 qualities were accounted The factual examination included 204 patients for the 1-2-year development, 212 patients for the 3-5year development, and 252 for the 6-10-year 
development. The extent of patients with grades $\mathrm{AB}$ and CD didn't contrast for any subsequent period between gatherings. At the point when just dissecting the radiographic appraisal of those investigations remembered for the KT-1000 arthrometer estimations, it was discovered that the TT bunch exhibited essentially more noteworthy tibiofemoral space narrowing contrasted with the AMP bunch at the 6-10-year followup.

Table (1) Summary of Studies.

\begin{tabular}{|c|c|c|c|c|c|c|c|c|}
\hline Study & $\begin{array}{c}\text { Fermoral } \\
\text { drilling }\end{array}$ & Design & $\begin{array}{c}\text { No. of } \\
\text { Patients }\end{array}$ & age & $\mathbf{m} / \mathbf{f}$ & $\begin{array}{l}\text { Time of } \\
\text { Follow - } \\
\text { up }\end{array}$ & Femoral fixation & Tibial fixation \\
\hline $\begin{array}{l}\text { Beard et } \\
\text { al.[9] }\end{array}$ & AMP & PNRCT & 30 & - & & $\begin{array}{l}6 \mathrm{mo} \\
12 \mathrm{mo}\end{array}$ & $\begin{array}{l}7 \times 25 \mathrm{~mm} \\
\text { interference screw }\end{array}$ & $\begin{array}{c}9 \times 25 \mathrm{~mm} \\
\text { Interference screw }\end{array}$ \\
\hline $\begin{array}{l}\text { Corry et } \\
\text { al. }[10]\end{array}$ & AMP & PRCT & 90 & 25 & $\begin{array}{c}48 \mathrm{~m} / \\
42 \mathrm{f}\end{array}$ & $\begin{array}{l}12 \mathrm{mo} \\
24 \mathrm{mo}\end{array}$ & $\begin{array}{l}\text { Round-headed } \\
\text { cannulated } \\
\text { interference screw }\end{array}$ & $\begin{array}{l}\text { Round-headed } \\
\text { cannulated } \\
\text { interference screw }\end{array}$ \\
\hline $\begin{array}{l}\text { Pinczewski } \\
\text { et al. [11] }\end{array}$ & AMP & PNRCT & 90 & 25 & $\begin{array}{c}48 \mathrm{~m} / \\
42 \mathrm{f}\end{array}$ & $\begin{array}{l}12 \mathrm{mo} ; \\
24 \mathrm{mo} ; \\
36 \mathrm{mo} \\
48 \mathrm{mo} \\
60 \mathrm{mo}\end{array}$ & $\begin{array}{c}7 \times 25 \mathrm{~mm} \\
\text { Cannulated } \\
\text { interference screw }\end{array}$ & $\begin{array}{c}7 \times 25 \mathrm{~mm} \\
\text { Cannulated } \\
\text { interference screw }\end{array}$ \\
\hline $\begin{array}{l}\text { Roe et al. } \\
{[12]}\end{array}$ & AMP & PNRCT & 90 & 25 & $\begin{array}{l}48 \mathrm{~m} / \\
42 \mathrm{f}\end{array}$ & $\begin{array}{l}12 \mathrm{mo} \\
24 \mathrm{mo} \\
60 \mathrm{mo} \\
84 \mathrm{mo}\end{array}$ & $\begin{array}{c}7 \times 25 \mathrm{~mm} \\
\text { Cannulated } \\
\text { interference screw }\end{array}$ & $\begin{array}{c}7 \times 25 \mathrm{~mm} \\
\text { Cannulated } \\
\text { interference screw }\end{array}$ \\
\hline $\begin{array}{l}\text { Wagner et } \\
\text { al.[13] }\end{array}$ & AMP & PNRCT & 55 & 33 & $\begin{array}{l}40 \mathrm{~m} / \\
42 \mathrm{f}\end{array}$ & $40 \mathrm{mo}$ & $\begin{array}{l}\text { Biodegradable } 8 \times \\
23 \mathrm{~mm} \text { Interference } \\
\text { screw }\end{array}$ & $\begin{array}{l}\text { Biodegradable } 8 \times \\
23 \text { mm Interference } \\
\text { screw }\end{array}$ \\
\hline $\begin{array}{l}\text { Sajovic et al. } \\
\text { (14) }\end{array}$ & AMP & PRCT & 26 & 27 & $\begin{array}{c}14 \mathrm{~m} / \\
12 \mathrm{f}\end{array}$ & $60 \mathrm{mo}$ & $\begin{array}{c}\text { Cannulated } \\
\text { interference screw }\end{array}$ & $\begin{array}{c}\text { Bioabsorbable } \\
\text { interference screw }\end{array}$ \\
\hline O'Neill [15] & TT & PRCT & 45 & 28 & $\begin{array}{c}28 \mathrm{~m} / \\
17 \mathrm{f}\end{array}$ & $39 \mathrm{mo}$ & $\begin{array}{l}9 \times 25 \mathrm{~mm} \\
\text { cannulated } \\
\text { interference screw }\end{array}$ & $\begin{array}{c}9 \times 25 \mathrm{~mm} \\
\text { Interference screw }\end{array}$ \\
\hline $\begin{array}{l}\text { Kleipool et } \\
\text { al. [16] }\end{array}$ & TT & PNRCT & 26 & 28 & $\begin{array}{c}9 \mathrm{~m} / 17 \\
\mathrm{f}\end{array}$ & $52 \mathrm{mo}$ & interference screw & interference screw \\
\hline $\begin{array}{l}\text { Anderson et } \\
\text { al. [17] }\end{array}$ & TT & PRCT & 35 & 23 & $\begin{array}{c}23 \mathrm{~m} / \\
12 \mathrm{f}\end{array}$ & $34 \mathrm{mo}$ & $\begin{array}{c}7 \times 25 \mathrm{~mm} \\
\text { interference screw }\end{array}$ & Two barbed staples \\
\hline $\begin{array}{l}\text { Aune et al. } \\
{[18]}\end{array}$ & TT & PRCT & 35 & 25 & $\begin{array}{c}19 \mathrm{~m} / \\
16 \mathrm{f}\end{array}$ & $\begin{array}{l}6 \mathrm{mo} \\
12 \mathrm{mo} \\
24 \mathrm{mo}\end{array}$ & $\begin{array}{c}7 \times 25 \mathrm{~mm} \\
\text { interference screw }\end{array}$ & $\begin{array}{l}\quad 7 \times 25 \mathrm{~mm} \\
\text { interference screw }\end{array}$ \\
\hline $\begin{array}{l}\text { Ejerhed et } \\
\text { al. [19] }\end{array}$ & $\mathrm{TT}$ & PRCT & 32 & 26 & $\begin{array}{l}11 \mathrm{~m} / \\
21 \mathrm{f}\end{array}$ & 24 mo; & $\begin{array}{c}7 \mathrm{~mm} \text { interference } \\
\text { screw }\end{array}$ & $\begin{array}{l}9 \mathrm{~mm} \text { interference } \\
\text { screw }\end{array}$ \\
\hline $\begin{array}{l}\text { Feller and } \\
\text { Webster [20] }\end{array}$ & $\mathrm{TT}$ & PRCT & 31 & 25 & $\begin{array}{c}23 \mathrm{~m} / 8 \\
\mathrm{f}\end{array}$ & $\begin{array}{l}8 \mathrm{mo} \\
12 \mathrm{mo} \\
24 \mathrm{mo} \\
36 \mathrm{mo}\end{array}$ & Endobutton & $\begin{array}{c}\text { Cannulated metallic } \\
\text { interference screw }\end{array}$ \\
\hline $\begin{array}{l}\text { Aglietti et al. } \\
{[21]}\end{array}$ & $\mathrm{TT}$ & PRCT & 60 & 25 & $\begin{array}{c}46 \mathrm{~m} / \\
14 \mathrm{f}\end{array}$ & $\begin{array}{l}4 \mathrm{mo} \\
12 \mathrm{mo} \\
24 \mathrm{mo}\end{array}$ & $\begin{array}{l}\text { Transcondylar } \\
\text { fixation through } \\
\text { tuneloc screw }\end{array}$ & $\begin{array}{c}\text { Soft threaded } \\
\text { interference screw }\end{array}$ \\
\hline $\begin{array}{l}\text { Gorschewsky } \\
\text { et al. [22] }\end{array}$ & TT & PNRCT & 136 & & & $\begin{array}{l}24 \mathrm{mo} \\
71 \mathrm{mo}\end{array}$ & $\begin{array}{c}\text { Bioabsorbable } \\
\text { interference screw }\end{array}$ & $\begin{array}{c}\text { Bioabsorbable } \\
\text { interference screw }\end{array}$ \\
\hline $\begin{array}{l}\text { Ibrahim et } \\
\text { al. [23] }\end{array}$ & TT & PRCT & 110 & 22 & & $81 \mathrm{mo}$ & interference screw & interference screw \\
\hline $\begin{array}{l}\text { Laxdal et al. } \\
{[24]}\end{array}$ & TT & PRCT & 40 & 28 & $\begin{array}{c}29 \mathrm{~m} / \\
11 \mathrm{f}\end{array}$ & $26 \mathrm{mo}$ & $\begin{array}{c}7 \text { mm Sharp } \\
\text { threaded } \\
\text { interference screw }\end{array}$ & $\begin{array}{c}9 \text { mm Sharp } \\
\text { threaded } \\
\text { interference screw }\end{array}$ \\
\hline $\begin{array}{l}\text { Matsumoto } \\
\text { et al. [25] }\end{array}$ & TT & PRCT & 37 & 23 & $\begin{array}{c}21 \mathrm{~m} / \\
16 \mathrm{f}\end{array}$ & $87 \mathrm{mo}$ & $\begin{array}{l}7 \times 20 \mathrm{~mm} \\
\text { interference screw }\end{array}$ & $\begin{array}{l}7 \times 20 \mathrm{~mm} \\
\text { interference screw }\end{array}$ \\
\hline $\begin{array}{l}\text { Maletis et al. } \\
{[26]}\end{array}$ & $\mathrm{TT}$ & PRCT & 46 & 27 & $\begin{array}{c}31 \mathrm{~m} / \\
15 \mathrm{f}\end{array}$ & $\begin{array}{l}6 \mathrm{mo} \\
12 \mathrm{mo} \\
24 \mathrm{mo}\end{array}$ & $\begin{array}{c}7 \times 23 \mathrm{~mm} \\
\text { Bioabsorbable } \\
\text { screw }\end{array}$ & $\begin{array}{c}9 \times 28 \mathrm{~mm} \\
\text { Bioabsorbable } \\
\text { interference screw }\end{array}$ \\
\hline
\end{tabular}

\section{Discussion}

The motivation behind this examination was to think about the distinctions in clinical results between the TT versus the AMP strategy for the femoral passage penetrating in the one-entry point arthroscopically helped single-group ACL reproduction. 
Given the nonappearance of any immediate correlation between the two procedures, this was a metaexamination dependent on circuitous examinations. The main finding of the current investigation was that the AMP bunch started running essentially before and had altogether more prominent ROM (for both knee augmentation and knee flexion) and front back knee dependability evaluated through both the Lachman test and the KT-1000 arthrometer at the 1-2-year development contrasted with the TT gathering, in spite of the fact that these distinctions were not kept up for the remainder of the development. Interestingly, the TTgroup showed more prominent action level at 3-5year and 6-10-year development contrasted with the AMP gathering. No distinctions were found for in general IKDC, Lysholm scores, turn move sign test, and radiographic evaluation. These outcomes may demonstrate a possible advantage of the AMP over the TT strategy for knee soundness, ROM, and re-visitation of run, in spite of the fact that there is no authoritative proof, now, to infer that one method is better than theother. Randomized controlled preliminaries straightforwardly contrasting the utilization of the two methods and long haul subsequent will help explain which one, assuming any, gives best clinical results.

This investigation inspired a marginally higher extent; be that as it may, not all examinations indicated the femoral boring technique. The quantity of TT strategy studies may increment if the boring technique was methodicallly depicted in completely distributed articles.

This audit included 13 investigations utilizing the TT strategy and included a sum of 602 patients. Subsequently, this example should be illustrative of the patients going through ACL remaking utilizing the TT penetrating of the femoral passage.

The two gatherings were profoundly similar as far as segment attributes, in this manner restricting potential puzzling elements identified with age and male:female proportions. Patients from the AMP bunch got back to run and full games sooner than the TT bunch regardless of the two gatherings had comparative recovery conventions. Early re-visitation of run and sports might be clarified by a more noteworthy knee capacity and security during first months after ACL remaking in the AMP gathering. The higher unite disappointment rates that were found in the AMP contrasted with the TT gathering ought to be deciphered with alert. Practically all unite disappointments were horrendous in nature, so join breaks might be more identified with the cooperation in physical games than the procedure itself.

In movement level, practically everything considers didn't report if the motivation not to partake in sports was legitimately identified with worries about the worked knee. It stays indistinct if the higher extent of stationary patients and patients partaking in low power practice in the AMP bunch is clarified by a helpless knee capacity or in light of psychosocial factors (dread for re-visitation of sports, changes in life conditions, and so forth) The absence of contrasts in the general IKDC or Lysholm scores may demonstrate that the lower movement level in the AMP bunch is identified with psychosocial factors that limit the possibility to take an interest in additionally requesting exercises. Be that as it may, the examination of the movement level and the IKDC and Lysholm was not actually founded on a similar example, so care must be taken when setting up direct connections among these factors. Subtleties on the motivation not to partake in sports are required in all examinations managing the ACL reproduction to guarantee a right understanding of the re-visitation of sports boundary.

The accomplishment in ACL recreation medical procedure is primarily dictated by similitudes between the unite morphology,tension, position, and direction contrasted with the local ACL. An anteriorly positioned unite brings about a front back insecurity of the knee, while a vertically arranged join in the coronal plane outcomes in an expanded inward revolution and positive rotate move sign .

Despite the fact that it was discovered that a posteriorly found join can be accomplished through the TT strategy, consequently halfway reestablishing the foremost back knee stability], a fundamentally more prominent transient front back knee strength in the AMP bunch contrasted with the TT bunch was found in this examination. The discoveries of this examination are in concurrence with Arnold et al, Paessler et al, and Dargel et al, who proposed that the TT method may put the femoral inclusion site of the unite more front regarding the local ACL side. Nonetheless, there were no front back knee strength contrasts between bunches for the $3-$ 5 and 6-10-year subsequent meet-ups.

Estimations of Lachman test and KT-1000 arthrometer for the AMP bunch were comparative in all subsequent meet-ups, while estimations of front back knee dependability in the TT bunch improved in the 3-5 and 6-10 years contrasted with the 1-2-year development. Expanded knee solidness in the mid-and long haul contrasted with the present moment development might be clarified by an expansion in knee osteoarthritic changes, ligamentization wonders that would not yet be available during the initial 2 years, and an improvement in the neuromuscular control (dynamic stabilizers) that would remunerate knee steadiness contrasts among gatherings. The most probable clarification might be an expansion in knee osteoarthritic changes in the TT bunch that may diminish knee laxity with time. Albeit no distinctions in radiographic evaluation were found between bunches for any subsequent period, the radiographic examination did not depend on a similar example than the knee steadiness investigation. Truth be told, when factually investigating the radiographic paramete for just those patients that were broke down with KT-1000 arthrometer, the TT bunch had more noteworthy long haul knee osteoarthritic changes (more prominent space narrowing) contrasted with the AMP gathering. Albeit no general contrasts in knee osteoarthritis were accounted for between gatherings, this may be a possible clarification for the expanded knee strength esteems in the TT bunch with 
time and, thusly, conceivably clarifying why knee steadiness contrasts found for the present moment development were not kept up in the mid-and long haul development.

The TT penetrating may deliver an all the more vertically arranged femoral passage contrasted with the AMP procedure. The slanted 10 o'clock position was found to more readily reestablish rotational knee steadiness contrasted with the 11 o'clock position. In spite of the fact that Rue et al. exhibited that a 10:20 position was feasible with the TT strategy, most examinations report that lone a 11 o'clock position is conceivable with the TT penetrating, while a 10 o'clock position can be accomplished with the AMP method.

One may anticipate from this proof that the AMP gathering would show more noteworthy rotational knee steadiness over the TT gathering. Be that as it may, no distinctions were distinguished for turn move sign qualities between the two procedures. The turn move sign test may have a high between spectator inconstancy.

Hence, the higher the quantity of doctors playing out the rotate move test are associated with an examination, the higher the inconstancy of the revealed results. Along these lines, the blend of various examinations with various analysts might be hard to accompany a huge distinction. Randomized controlled preliminary straightforwardly contrasting the AMP with the TT method with less between onlooker fluctuation would better clarify if rotational knee solidness esteems do vary between the two strategies.

ROM at present moment development was fundamentally better in the AMP contrasted with the TT gathering. It very well may be contended that a good passage situation would support better reclamation of ROM. Notwithstanding, mid-and long haul subsequent discoveries for ROM were not diverse between gatherings. It appears to be far-fetched that distinctions in burrow situation would clarify a more prominent ROM in the 1-2-year development if contrasts are not kept up with time.

There are a few impediments to this investigation that must be remembered when deciphering these outcomes. To start with, and premier, this metainvestigation depended on aberrant examinations. The utilization of roundabout correlations is disputable, in spite of the fact that the absence of direct relative examinations between the two strategies makes this investigation to be the main guide now to analyze the femoral boring method in the BPTB ACL reproduction. Given the expanding interest of whether utilizing the AMP or the TT procedure for making the femoral passage in the ACL remaking medical procedure, this examination might be of interest for muscular specialists. Second, there was a low homogencity when revealing a portion of the results. As an outcome, not all examinations had the option to be remembered for the factual investigation of specific boundaries in light of the fact that the count of impact sizes in the included investigations was impractical given that they didn't utilize the equivalent comparators.
Nonetheless, the insights for all the results were finished with a high number of patients, consequently diminishing the danger of arbitrary mistake. Third, the half of the investigations in the AMP bunch came from a similar gathering of Pinczewski, and every one of them alluded to a similar example. It very well may be contended that the example for the AMP bunch was profoundly homogeneous, in this way diminishing the outside legitimacy of the outcomes. Nonetheless, the separation of the results in 3 subsequent periods and the consideration of information from the gathering of Pinczewski once at each development may have restricted this worry. At last, as various investigations were included, various specialists and doctors playing out the actual assessment were selected. This might be a wellspring of between study changeability, especially in boundaries like the turn move sign test or the careful method itself (i.e., the femoral passage position in the coronal plane). Randomized controlled preliminaries ought to be led to analyze the AMP and the TT procedures to all the more likely clarify the impacts of the femoral passage penetrating technique on the clinical results. Th technique.

\section{References}

[1] E .Alentorn-Geli, G.D. Myer, H.J. Silvers, G. Samitier, D. Romero, C. Lázaro-Haro, R. Cugat , Prevention of non-contact ante- rior cruciate ligament injuries in soccer players. Part 1: mechanisms of injury and underlying risk factors. Knee Surg Sports Traumatol Arthrosc, Vol.17, PP.705729,2009 .

[2] B.Saccomanni, Graft fixation alternatives in anterior cruciate ligament reconstruction. Musculoskelet. Surg, Vol.95(3), PP.183-191,2011.

[3] F.Rayan, S.K.Nanjayan, C.Quah, D.Ramoutar, S.Konan, F.S. Haddad, Review of evolution of tunnel position in anterior cruciate ligament reconstruction. World J. Orthop , Vol.6(2), PP.252262,2015.

[4] P.Sadoghi, A.Kröpfl, V.Jansson, P.E.Müller, M.F.Pietschmann, M.F. Fischmeister Impact of tibial and femoral tunnel position on clinical results after anterior cruciate ligament reconstruction. Arthroscopy, Vol.27(3), PP. 355-364,2011.

[5] G.V.Kamath, J.C.Redfern, P.E.Greis, R.T. ,Burks Revision anterior cruciate ligament reconstruction.Am. J. Sports Med, Vol.39(1), PP.199-217,2011.

[6] Eduard alentorn-geli, gonzalo samitier ,anteromedial portal versus transtibial drilling techniques in acl reconstruction: a blinded crosssectional study at two- to five-year follow-up. int orthop. june, Vol.34(5), PP. 747-754,2010.

[7] A.L.Silva, R .sampaio, E.pinto acl reconstruction: comparison between transtibial and anteromedial portal techniques. knee surg sports traumatol arthrosc, Vol.20(5), PP.896-903,2012. 
[8] L.S. Lohmander, P.M. Englund, L.L. Dahl, E.M .Roos , The long-term consequence of anterior cruciate ligament and menis- cus injuries: osteoarthritis. Am J Sports Med, Vol.35, PP.17561769,2007.

[9] D.J. Beard, J.L. Anderson, S. Davies, A.J .Price, C.A.F. Dodd , Hamstrings versus patella tendon for anterior cruciate ligament reconstruction: a randomised controlled trial. Knee , Vol.8, PP.45$50,2001$.

[10]I.S. Corry , J.M.Webb , A.J. Clingeleffer , L.A. Pinczewski, Arthroscopic reconstruction of the anterior cruciate ligament. A comparison of patellar tendon autograft and four-strand hamstring tendon autograft. Am J Sports Med, Vol.27, PP.444-454,1999.

[11]L.A. Pinczewski, J. Lyman, L.J. Salmon, V.J. Russell, J. Roe, J. Link- later , A 10-year comparison of anterior cruciate ligament reconstructions with hamstring tendon and patellar tendon auto- graft: a controlled, prospective trial. Am J Sports Med, Vol.35, PP.564- 574,2007.

[12] J .Roe, L.A. Pinczewski, V.J. Russell, L.J. Salmon, T. Kawamata, M. Chew, A 7-year follow-up of patellar tendon and hamstring tendon grafts for arthroscopic anterior cruciate liga- ment reconstruction. Differences and similarities. Am J Sports Med, Vol.33, PP.1337-1345,2005.

[13] M. Wagner, M.J. Ka“a”b, J .Schallock, N.P. Haas, A .Weiler, Hamstring tendon versus patellar tendon anterior cruciate liga- ment reconstruction using biodegradable interference fit fixation. A prospective matched-group analysis. Am J Sports Med, Vol.33, PP.1327-1336,2005.

[14] M .Sajovic, V .Vengust, R .Komadina, R .Tavcar, K. Skaza, A prospective, randomized comparison of semitendinosus and gracilis tendon versus patellar tendon autografts for anterior cruciate ligament reconstruction. Five-year follow-up. Am J Sports Med, Vol.34, PP.1933-1940,2006.

[15]D.B. O'Neill ,Arthroscopic assisted reconstruction of the anterior cruciate ligament. A prospective randomized analysis of three techniques. J Bone Joint Surg Am , Vol.78, PP.803-813,1996.

[16]A.E.B. Kleipool , J.A.C. Zijl , W.J . Willems , Arthroscopic anterior cruciate ligament reconstruction with bone-patellar ten- don-bone allograft or autograft. A prospective study with an average follow up of 4 years. Knee Surg Sports Traumatol Arthrosc, Vol.6, PP.224-230, 1998.

[17] A.F. Anderson, R.B. Snyder, A.B. Lipscomb , Anterior cruciate ligament reconstruction. A prospective randomized study of three surgical methods. Am J Sports Med, Vol.29, PP.272279,2001 .

[18] A.K. Aune, I .Holm, M.A. Risberg, H.K. Jensen, H. Steen, Four-strand hamstring tendon autograft compared with patellar tendon-bone autograft for anterior cruciate ligament reconstruc- tion. A randomized study with two-year follow-up. Am J Sports Med, Vol.29, PP.722-728,2001.

[19]L .Ejerhed, J .Kartus, N. Sernert, K. Kohler, J .Karlsson , Patellar tendon or semitendinosus tendon autografts for anterior cruciate ligament reconstruction? A prospective randomized study with a two-year follow-up. Am J Sports Med, Vol.31, PP.19-25,2003.

[20]J.A. Feller , K.E. Webster , A randomized comparison of patellar tendon and hamstring tendon anterior cruciate ligament reconstruction. Am J Sports Med, Vol.31, PP.564-573,2003.

[21] P .Aglietti, F. Giron, R .Buzzi, F. Biddau, F. Sasso ,Anterior cruciate ligament reconstruction: bonepatellar tendon-bone compared with double semitendinosus and gracilis tendon grafts. A prospective, randomized clinical trialth. J Bone Joint Surg Am, Vol.86, PP.2143-2155,2004.

[22] O. Gorschewsky , A. Klakow , K. Riechert , M. Pitzl , R .Becker, Clinical comparison of the Tutoplast allograft and autol- ogous patellar tendon (bone-patellar tendon-bone) for the reconstruction of the anterior cruciate ligament. Two- and 6-year results. Am J Sports Med, Vol.33, PP.1202-1209 , 2005.

[23] S.A.R. Ibrahim, I.M. Al-Kussary, A.R.K. Al-Misfer, H.Q. Al-Mutairi, S.A. Ghafar, T.A. El Noor , Clinical evaluation of arthro- scopically assisted anterior cruciate ligament reconstruction: patellar tendon versus gracilis and semitendinosus autograft. Arthroscopy, Vol.21, PP.412-417,2005.

[24] G. Laxdal, J .Kartus, L .Hansson, M .Heidvall, L. Ejerhed, J .Karlsson, A prospective randomized comparison of bone-patellar tendon-bone and hamstring grafts for anterior cruciate ligament reconstruction. Arthroscopy, Vol.21, pp. 3442,2005.

[25]A .Matsumoto , S.Yoshiya , H. Muratsu , M. Yagi , Y. Iwasaki , M .Kurosaka, R. Kuroda () A comparison of bone-patellar tendon-bone and bonehamstring tendon-bone autografts for anterior cruciate ligament reconstruction. Am J Sports Med, Vol.34, PP.213-219,2006.

[26]G.B. Maletis, S.L. Cameron, J.J. Tengan, R.J .Burchette, A prospective randomized study of anterior cruciate ligament reconstruction. A comparison of patellar tendon and quadrupledstrand semitendinosus/gracilis tendons fixed with bioabsorbable interference screws. Am J Sports Med, Vol.35, PP.384-394,2007. 